\title{
Consummatory Taste Reward in Obesity
}

\author{
Jonathan B. Simon ${ }^{1}$, Ghalia N. Abdeen ${ }^{1}$, Alexander D. Miras ${ }^{2,3,{ }^{*}}$ and Carel W. le Roux ${ }^{2,4}$ \\ ${ }^{1}$ Imperial College London, South Kensington Campus, London SW7 2AZ, UK \\ ${ }^{2}$ Imperial Weight Centre, Imperial College London, UK \\ ${ }^{3}$ Molecular and Metabolic Imaging Group, MRC Clinical Sciences Centre, Imperial College London, UK \\ ${ }^{4}$ Experimental Pathology, Conway Institute, School of Medicine and Medical Science, University College \\ Dublin, Ireland
}

\begin{abstract}
Obesity is a disease of multiple origins and results from the interaction between the genetic predisposition of a person and environmental factors, including food preferences. Even though the literature is not always consistent, there is strong support for the notion that the obese do not just consume more calories, but also prefer calorifically dense foods. In this review, the evidence for differences in the consummatory reward of taste, and in particular sweet and fat taste, will be examined in the context of food preferences in obesity.
\end{abstract}

Keywords: Fat, sweet, food preferences, behavioural, taste reactivity.

\section{INTRODUCTION}

Obesity is considered the disease of the $21^{\text {st }}$ century and its prevalence has increased dramatically in the last three decades globally in developing countries as well as the developed world, from urban to rural areas for both adults and children. Over 400 million people are presently diagnosed as obese, having a body mass index (BMI) $\geq 30 \mathrm{~kg} / \mathrm{m}^{2}$ and almost 1.6 billion are overweight (BMI $\left.25-29.9 \mathrm{~kg} / \mathrm{m}^{2}\right)$ [1]. This increasing prevalence of obesity has already raised and will continue to worsen the rates of diabetes, hypertension, heart disease, osteoarthritis, cancer, and other chronic diseases. What these data lack to state, is the fact that every person, not just the obese, is affected by this epidemic [2]. It has increased health care costs, affecting the health care industry as well as other economic sectors that have no direct relationship to health care [3].

Obesity is a disease of multiple origins and results from the interaction between the genetic predisposition of a person and environmental factors, including diet pattern. Many studies have evaluated the relative contributions of genetics and environment to the aetiology of obesity. BMI variability amongst humans can be explained by 30 to $40 \%$ due to genetics and 60 to $70 \%$ due to the environment according to some studies. Stunkard, for example, found that the genotype of some people who are genetically prone to develop obesity may be expressed only under certain adverse

*Address corresponding to this author at the Imperial Weight Centre, Fulham Palace Road, London W6 8RF, UK; Tel: 00447958377674;

Fax: 00442033130673; E-mail: a.miras@nhs.net environmental conditions, such as exposure and consumption of high-fat diets and a sedentary lifestyle [4]. Childhood risk factors for obesity also include social factors, parental obesity, high birth weight, earlier onset of maturity and behavioural or psychological factors amongst others [5]. The mechanisms preventing an obese person from losing weight and maintaining weight loss have only been partially elucidated [6].

\section{DETERMINANTS OF FOOD PREFERENCES}

Social, cultural and genetic factors contribute to the development, preservation and alteration of dietary patterns and food preferences, taste, and food choices $[7,8]$. Interpersonal similarities such as in a family and group do influence eating behavior and exert direct or indirect social influences (e.g. beliefs, cooking traditions, food rules which a family may teach their children).

Taste and other sensory properties of foods (e.g. smell and texture) are partly responsible for the selection of one food over another. Hedonic value is the result of the relation between the reward value of a food and the immediate psychological and physiologic status of a subject $[9,10]$. The hedonic reward value of food is strongly linked to the perception of taste, which may be a driving force behind food consumption [11]. Food likes and dislikes are influenced by physiological factors, similar to those that determine hunger and satiety but also biological learning. The liking of food is also acquired after experiencing positive post-ingestive effects of intake. The "conditioned taste aversion" refers to the acquisition of a strong negative response after the intake of a specific food has been followed by 
a digestive side effect. These sensory cues can affect food choices from birth to old age [12]. The dissimilarity in taste papillae density and the genetic differences on taste receptors that may affect the taste sensitivity and salivation do contribute to a person's taste acuity and perhaps food preferences [13].

\section{THE TASTE SYSTEM}

The taste receptors that are located in the mouth and small intestine are responsible for originating "taste signals" [14]. Once in the mouth, the food ingredients act together with the receptors on taste cells positioned on the taste buds in the tongue to provide information regarding their identity, concentration and pleasant or unpleasant features. The signals prepare the gastrointestinal system to accept the food by the processes of salivation and swallowing or to refuse it by gagging and regurgitation if the substance is harmful or toxic [15]. The taste receptor cells react specifically to the different taste modalities [16]; sweet, salt, bitter, sour and umami (glutamate). The recognition of fat taste is controversial, but there is growing evidence that fat stimuli can be detected by the gustatory system [17].

The primary taste cortex, including the frontal operculum and anterior insula receive the first signals, with their neurons reacting to taste modalities without encoding taste reward. The secondary taste cortex that includes the orbitofrontal cortex (OFC) and the amygdala are responsible for encoding the reward value of taste. Additional signals from the OFC reach the hypothalamus, the homeostatic control of feeding, to trigger autonomic and hormonal responses, including the release of insulin [13].

The complex network of taste can be better understood if broken down in three domains [18]:

1. The sensory domain: this encompasses the detection function of the taste system, (i.e. is this food sweet and if so how sweet is it?)

2. The reward domain: this incorporates the appetitive (how much effort am I willing to exert to obtain this sweet taste?) and the consummatory sub-domains (how rewarding is this sweet taste?)

3. The physiological domain: this describes the physiological processes that take place when a tastant is in the oral cavity (i.e. sweet taste causing salivation or a cephalic insulin response).
Even though the literature is not always consistent, there is strong support for the notion that the obese do not just consume more calories, but also prefer calorifically dense foods [19-29]. In this review, the evidence for differences in the consummatory reward of taste, and in particular sweet and fat taste, will be examined in the context of food preferences in obesity.

\section{OBESITY AND THE CONSUMMATORY REWARD OF SWEET AND FAT TASTE}

\section{Sweet}

In 1973 Underwood tested 18 obese and 11 lean adults by randomly administering $10-400 \mathrm{~g}$ of sucrose/l before and 1 hour after a $50 \mathrm{~g}$ glucose load [30]. There was no change in the pleasantness ratings in the obese group whereas the change was significant in the lean group which found the sucrose solutions aversive. Unexpectedly the majority of participants rated the sucrose solution unpleasant even before the glucose load. The results of this small trial supported Cabanac's theory of decreased sensitivity to internal signals in obesity.

Rodin performed a series of experiments on taste responsiveness [31]. In the first one she recruited 53 female participants and divided them into 4 groups: normal weight, low overweight, overweight and obese. They were randomly presented with 6 ascending concentrations of glucose $(0.125-3 \mathrm{M})$ in 4 trials using the sip and spit technique. In two of the trials, the participants rated the pleasantness using a 9 point scale. The test was performed mid-afternoon 3 hours after a $500 \mathrm{Kcal}$ lunch. Participants were tested at baseline and in the last week of an 8 week weight reduction programme of daily exercise and caloric restriction. Normal weight group found high sucrose concentrations $(>1 \mathrm{M})$ less pleasant compared to the overweight groups. This is in contrast to other studies which showed no differences in valence ratings between overweight and normal weight subjects [32, 33] and may be a reflection of the different tastants used, ranging from sucrose flavoured water to chocolate milkshakes [32, 34]. Following weight loss pleasantness ratings did not change in any of the groups.

In the second she recruited 11 obese females and tested them before and 6 months after jejunoileal bypass (JIB) surgery for obesity. Subjects were again asked to rate the pleasantness of ascending concentrations of glucose, salt, citric acid and quinine representing the 4 modalities of taste. Intensity ratings 
for glucose did not change after surgery. Pleasantness ratings were variable pre operatively with no consistent pattern whereas after surgery pleasantness ratings were consistently high for most concentrations of sweet apart from the $3 \mathrm{M}$ one which was lower. The post op curve resembled the response of normal weight individuals from similar experiments. The responses for the other taste modalities did not change. The authors did not explain why the results of the pre-JIB group were not consistent yet go ahead and try and interpret the post op results in which the same methodology was used and concluded that the reduced preference of high glucose solutions may be only partially explained by the "dumping" phenomenon and conditioned taste aversion but also probably by other "peripheral mechanisms". Opposite to the views of Nisbett and Schachter, who consider taste as an external cue, Rodin supports Cabanac's views and suggests that interpretation of taste is influenced by internal changes including hunger, reduced fat mass or surgical interventions for example.

In the last experiment 30 overweight and 30 obese patients from experiment 1 were compared to 6 normal weight controls before and after the same weight loss programme. They were asked to rate the pleasantness of a chocolate milkshake's sweet taste, thickness and creaminess before or 45 minutes after a $500 \mathrm{Kcal}$ preload of sandwich, fruit and milk. Before weight loss there were no differences in ratings before or after the preload amongst the groups. After weight loss the pleasantness ratings before a preload were identical to the ratings before weight loss, but the rating after the preload were higher in all groups to those made before weight loss. These results support the notion that in the deprived state internal signals to short term changes (preload) are ignored and the subject rates sweet food as highly pleasant. The degree of obesity did not alter these responses, suggesting that any decrease of adiposity away from the set point has similar results on increasing the pleasantness of sweet taste. The most helpful point this experiment makes is that in the deprived state, feeding increases the affective attributes of sweet taste. Interestingly, these attributes do not differ between lean and obese participants. The study does actually support Nisbett's concept of sweet taste becoming more rewarding after adipose tissue losses, the only difference being that this applies to any weight category, lean or obese [35].

Frijters [36] studied 13 overweight females and compared them to 12 normal weight subjects in terms of sweet taste detection, intensity, pleasantness and preference. Using the constant stimuli and sip and spit methods, 18 sweet stimuli made of sugar diluted in distilled water and ranging from 0.0006 to $0.02 \mathrm{M}$, were presented randomly in one session. The pleasantness of the 18 solutions was determined on a different session in which subjects rated them on a $170 \mathrm{~mm}$ scale with the anchor "ideal" in the middle, "not liked as not sweet enough" on the left and "not liked as too sweet" on the right. The curves obtained from these ratings and the maximal sweetness preference did not change between the groups even thought there was a trend for overweight subjects to rate every solution as more pleasant compared to the normal weight subjects and the maximally pleasant sweet concentration was higher in the obese group compared to the normal weight group $(0.1912$ vs. $0.1542 \mathrm{M})$. Possible confounders include the recruitment of overweight but not obese patients and the use of sugar solutions in water at room temperatures which does not relate to everyday food items.

A similar "just about right" (JAR) scale was successfully used by Conner and Booth in 1988 [37] and shown to correlate strongly with sweet food consumption in 344 young volunteers with only very few of them in the overweight or obese weight range. Lime drinks were presented in one setting in room temperature and mixed with sugar to make six $20 \mathrm{ml}$ sweet concentrations. Each subject was presented with only 3 samples. After tasting the subjects pointed to a scale made of boxes which were numbered from 1 to 9 : Box 1 was assigned the label "so little sweetness l'd never choose to drink it", Box 5 "Sweetness just right for me" and Box 9 "so much sweetness that l'd never chose to drink it" and the responses were shown to be linear with a positive slope against the log sugar concentration. The mean ideal point was $0.12 \mathrm{M}$ (similar to the concentration of cola). The ideal point correlated positively with the amount of sugar they added to hot drinks and preference for sweet foods as obtained from food choices questionnaires. Additionally men were found to have a higher preference for sweets compared to women and BMI did not correlate with these preferences. The large sample size and the use of a lime drink which is closer to a real life beverage was an advantage of the study, although the investigators were not blinded to the testing solutions as they chose the stimuli used to obtain the best fit to the linear plot for each subject.

\section{Sweet Intensity and Consummatory Reward Using the General Labelled Magnitude Scale}

Linda Bartoshuk reviewed the above literature and improved the ways scaling experiments are performed 
[38]. Firstly, she has shown that taste detection thresholds do not predict food preferences and for the comparison of obese with normal weight subjects suprathreshold concentrations should be used [39, 40]. Secondly, both visual analogue scales and nine point category magnitude scales for intensity and hedonic characteristics of food or taste assume wrongly that the labels used denote the same experience amongst different subjects. A good example is that of pain; the "most intense pain ever experienced" label on such a scale is very different to women who have experienced the pain of childbirth compared to men who never have. Guiding analgesia treatment based on such a scale would result in lower medication doses being given to women.

The solution proposed was the use of the general labelled magnitude scale (gLMS) in which the labels include phrases like "strongest sensation ever experienced". This way the modality tested is not mentioned in the scale and the subject is allowed to rate it based on comparison with their own strongest sensation ever experienced (i.e. pain, brightness, loudness), which can now act as a standard for intensity. The gLMS can therefore be used to compare intensity of taste in a valid manner between nontasters, medium tasters and super tasters. The spacing of the labels on the scale is such that for example a rating of $70 \mathrm{~mm}$ in a $200 \mathrm{~mm}$ scale denotes intensity double from a rating of $35 \mathrm{~mm}$. This methodology has been used for the development of hedonic scales using the anchors "strongest imaginable disliking/liking" on either side of a $200 \mathrm{~mm}$ scale with "neutral in the middle". The application of these concepts showed that intensity of sweet decreases with increasing BMI. Using the hedonic form of the gLMS, Bartoshuk also showed that the "liking" for sweet taste increased as a function of BMI. Her results are in line with those of Moskowitz [41] who by plotting liking against perceived sweetness showed that for the same perceived sweetness, hedonic liking goes up as BMI increases.

\section{Fat}

Further investigations on fat reward have been conflicting in their results, similar to the sugar story. Pangborn studied 186 women who were underweight, normal weight or overweight using different concentrations of fat in milk [42]. Hedonic ratings did not differ between the three groups. Discrimination between different fat concentrations proved to be very poor. In terms of food diaries, the frequency of consumption of food high in fat was higher in the overweight when compared to the underweight group only. The most reproducible results came from a behavioural task in which participants were asked to mix different milk types to a mix of their liking. Subjects who consumed higher amounts of fat in their food diaries also mixed to higher concentrations of fat in milk during the task compared to those consuming less fat from their food diaries [42].

Mela studied 30 women with food diaries and pleasantness ratings after consumption of fat products [43]. He found wide variations between individuals in their most preferred fat level and no correlation of these preferences with the stimuli used. However, a positive correlation between overall fat preference and percent body fat was found, albeit it's small magnitude. This finding is questionable considering the presence of high variability in this experiment.

\section{Fat and sweet}

In an attempt to explain the discrepant results of previous investigators (obese finding sweet taste more pleasant [31, 34, 44, 45] and no changes in sweet taste in reward in obesity [30, 32, 40, 45-49], Drewnonski [50] suggested that the differences were due to the nature of the different stimuli used and that it is the combination of sweet with fat taste as experienced in everyday life that should be the subject of further investigation. Indeed he recruited 12 female obese, 8 reduced obese (following a minimum of $13.6 \mathrm{~kg}$ weight loss through a low calorie diet) and 15 normal weight subjects. Buttock fat biopsies were taken and adipose cell size and lipoprotein lipase (LL) activity were measured. Participants were presented with 20 chilled fat and sugar samples containing a mixture of 5 ascending concentrations of fat and 4 ascending concentrations of sugar and made up to $10 \mathrm{mls}$. Subjects rated the pleasantness of sweet, fat and creamy in 9 point category scales. The stimuli were presented after a balanced meal and a 6-12 hour fast. In order to quantify the hedonic responses the authors used the Response Surface Method, a model which assumes that reward responses are a function of sweet and fat and created a 3 dimensional surface from interpolating data from the 20 stimuli used. In the normal weight group ratings increased up to a maximum sweetness of $10 \%$ sucrose followed by a drop and the same pattern is seen for fat up to $20 \%$ lipid followed by a drop. The predicted maximum pleasantness rating for this group was $7.7 \%$ sweet and $20.7 \%$ fat. 
Obese patients "liked" highly sweet and fatty solutions but "disliked" equally sweet solutions in a low fat mixture. For the same concentration of fat, the sweeter the solution the lower the pleasantness, results similar to those obtained by Underwood [30]. Maximum pleasantness ratings were obtained for the combination of $34.4 \%$ fat and $4.4 \%$ sweet. Finally subjects after weight loss reported a paradoxical reduction in pleasantness along all fat concentrations at low sweetness but a heightened pleasure from higher concentrations of sweetness at low fattiness. The maximum pleasantness rating was estimated at $35.1 \%$ fat, i.e. similar to the obese group and at $10.1 \%$ sweet, significantly higher than the obese group. This suggests that weight loss leads to increased valence of sweet when this is combined with fat. There were no correlations between optimal sweet/fat ratios and LL activity per adipose cell. This study combined ingredients, making them more applicable to everyday food experiences and acknowledging the effect fat texture can have on tasting, but did lack information on age, weight loss, average ratings in the fed and fasted state and a description of the meal provided.

Pima Indians who have a high risk for developing obesity, rated solutions of milk containing different concentrations of fat and sugar in a study conducted by Salbe and showed their hedonic responses were significantly lower than the white control population which was at lower risk for obesity [51].

\section{DISCUSSION AND CONCLUSIONS}

The majority of the published studies have used scaling methodology to assess consummatory reward. Scales are useful as they are easy to explain, use and are quick to interpret. However the limitations include the participant's own interpretation of their sensation and are thus subject to variation based on individual differences in prior sensory experience. The subjective interpretation of internal processes may lead to false reporting [52], which may be more of an issue in the context of obesity which still carries significant social stigma. The result may be large coefficient of variability, especially in between-group comparisons [53], leading to the discrepant results.

The solution to this problem may be the use of behavioural tasks, which may be more objective when studying human feeding behaviour. Facial reactivity is "the involuntary, minute movements of the face in response to a stimulus" [54]. These can be studied to enable an impression of the emotional state of an individual as a consequence of the applied stimulus. Taste reactivity studies using facial expression which looked at infants, apes, new world monkeys and rats concluded that there were two major reaction patterns seen. The positive, hedonic reaction - typically to sweet taste - was characterised by lip smacking, tongue protrusion and even a smile, while the negative (aversive) reaction to bitter taste involved grimacing, retracting of the lips, wrinkling of the nose and retraction of the head away from the food source. Other tastes, such as salt or sour, were found to produce responses with intermediate reactions between these two [55-59].

The use of taste reactivity to study the consummatory reward function of taste in human adults has been less well investigated. Previous work have shown that adults do demonstrate facial reactivity, with some promising results $[56,58,60,61]$ though it was considered that they may not be as accurate as a consequence of socialisation and voluntary or higher control $[58,62]$. Taste reactivity has not been used for the study of consummatory reward in obese adults as yet.

The major limitation to the use of facial reactivity is the difficulty in interpretation of these often small and subtle movements [58]. A few studies have used Facial Action Coding System (FACS) with trained interpreters [63]. However, recently new face recognition software packages have been developed that enable the more objective assessment of facial reactivity and the duration of the facial reaction, providing a better overall feedback on the emotional state of the subject (e.g. FaceReader ${ }^{\mathrm{TM}}$ ). This technology is promising and could be further improved in terms of specificity, sensitivity and adapted to cultural and social facial reactivity differences.

Functional neuroimaging, using positron emission tomography or functional magnetic resonance imaging (fMRI), is increasingly used to indirectly assess brain reward area activation to taste stimuli. Only a few studies have been performed in obesity and they suggest that the obese show differential reward centre activation compared to normal weight participants [64, 65]. Such novel techniques could compliment behavioural tasks and allow the in depth interrogation of the neural mechanisms contributing to obesity and resisting weight loss.

In conclusion, a number of studies have attempted to answer the question of whether the obese have different reward responses to fat and sweet taste and 
whether this is the result or cause of their obesity. There are significant discrepancies in the results of these studies, suggesting firstly that obesity is not a homogeneous condition and that traditional methodologies may introduce further unwanted variation in the investigation of taste reward. Our research methods will need to be improved and complimented by multimodal techniques in order to allow us to understand and treat this complex condition more effectively.

\section{ACKNOWLEDGEMENTS}

ADM is funded by the Medical Research Council Research Training Fellowship G0902002. There are no conflicts of interest in relation to this work.

\section{REFERENCES}

[1] WHO. Fact sheet: obesity and overweight. 2006; Available from: $\quad$ http://www.who.int/mediacentre/factsheets/fs311/ en/index.html.

[2] Pi-Sunyer FX. Medical hazards of obesity. Ann Intern Med 1993; 119 (7 Pt 2): 655-60.

[3] Kottke TE, Wu LA, Hoffman RS. Economic and psychological implications of the obesity epidemic. Mayo Clin Proc 2003; 78(1): 92-4.

http://dx.doi.org/10.4065/78.1.92

[4] Stunkard AJ. The Salmon lecture. Some perspectives on human obesity: its causes. Bull NY Acad Med 1988; 64(8): 902-23.

[5] Parsons TJ, Power C, Logan S, Summerbell CD. Childhood predictors of adult obesity: a systematic review. Int J Obes Relat Metab Disord 1999; 23(Suppl 8): S1-107.

[6] James WP. The fundamental drivers of the obesity epidemic. Obes Rev 2008; 9(Suppl 1): 6-13. http://dx.doi.org/10.1111/j.1467-789X.2007.00432.x

[7] Grimm ER, Steinle NI. Genetics of eating behavior: established and emerging concepts. Nutr Rev 2011; 69(1): 52-60.

http://dx.doi.org/10.1111/j.1753-4887.2010.00361.x

[8] Eertmans A, Baeyens F, Van den Bergh O. Food likes and their relative importance in human eating behavior: review and preliminary suggestions for health promotion. Health Educ Res 2001; 16(4): 443-56.

http://dx.doi.org/10.1093/her/16.4.443

[9] Blundell JE, Gillett A. Control of food intake in the obese. Obes Res 2001; 9(Suppl 4): 263S-70S. http://dx.doi.org/10.1038/oby.2001.129

[10] Mela DJ. Determinants of food choice: relationships with obesity and weight control. Obes Res 2001; 9(Suppl 4): 249S-55S.

http://dx.doi.org/10.1038/oby.2001.127

[11] Drewnowski A. Taste preferences and food intake. Annu Rev Nutr 1997; 17: 237-53.

http://dx.doi.org/10.1146/annurev.nutr.17.1.237

[12] Bellisle F. Why should we study human food intake behaviour? Nutr Metab Cardiovasc Dis 2003; 13(4): 189-93. http://dx.doi.org/10.1016/S0939-4753(03)80010-8

[13] Rolls ET. Taste, olfactory and food texture reward processing in the brain and obesity. Int J Obes (Lond) 2011; 35(4): 55061.

http://dx.doi.org/10.1038/ijo.2010.155
[14] Chandrashekar J, Hoon MA, Ryba NJ, Zuker CS. The receptors and cells for mammalian taste. Nature 2006; 444(7117): 288-94. http://dx.doi.org/10.1038/nature05401

[15] Purves D, Augustine GJ, Fitzpatrick D, et al., editors. Neuroscience. 2nd ed: Sunderland (MA): Sinauer Associates 2001.

[16] Yarmolinsky DA, Zuker CS, Ryba NJ. Common sense about taste: from mammals to insects. Cell 2009; 139(2): 234-44. http://dx.doi.org/10.1016/j.cell.2009.10.001

[17] Mattes RD. Accumulating evidence supports a taste component for free fatty acids in humans. Physiol Behav $2011 ; 104(4)$ : 624-31. http://dx.doi.org/10.1016/j.physbeh.2011.05.002

[18] Spector AC, Glendinning JI. Linking peripheral taste processes to behavior. Curr Opin Neurobiol 2009; 19(4): 370-7.

http://dx.doi.org/10.1016/j.conb.2009.07.014

[19] Drewnowski A, Kurth C, Holden-Wiltse J, Saari J. Food preferences in human obesity: carbohydrates versus fats. Appetite 1992; 18(3): 207-21. http://dx.doi.org/10.1016/0195-6663(92)90198-F

[20] Macdiarmid JI, Vail A, Cade JE, Blundell JE. The sugar-fat relationship revisited: differences in consumption between men and women of varying BMI. Int $\mathrm{J}$ Obes Relat Metab Disord 1998; 22(11): 1053-61. http://dx.doi.org/10.1038/sj.ijo.0800724

[21] Cox DN, van Galen M, Hedderley D, Perry L, Moore PB, Mela DJ. Sensory and hedonic judgments of common foods by lean consumers and consumers with obesity. Obes Res 1998; 6(6): 438-47.

http://dx.doi.org/10.1002/j.1550-8528.1998.tb00376.x

[22] Cox DN, Perry L, Moore PB, Vallis L, Mela DJ. Sensory and hedonic associations with macronutrient and energy intakes of lean and obese consumers. Int J Obes Relat Metab Disord 1999; 23(4): 403-10.

http://dx.doi.org/10.1038/sj.ijo.0800836

[23] Berry EM, Hirsch J, Most J, Thornton J. The role of dietary fat in human obesity. Int J Obes 1986; 10(2): 123-31.

[24] Kulesza W. Dietary intake in obese women. Appetite 1982; $3(1): 61-8$. http://dx.doi.org/10.1016/S0195-6663(82)80037-8

[25] Kromhout D. Energy and macronutrient intake in lean and obese middle-aged men (the Zutphen study). Am J Clin Nutr 1983; 37(2): 295-9.

[26] Dreon DM, Frey-Hewitt B, Ellsworth N, Williams PT, Terry RB, Wood PD. Dietary fat: carbohydrate ratio and obesity in middle-aged men. Am J Clin Nutr 1988; 47(6): 995-1000.

[27] Romieu I, Willett WC, Stampfer MJ, et al. Energy intake and other determinants of relative weight. Am J Clin Nutr 1988; 47(3): 406-12.

[28] Lissner L, Lindroos AK, Sjostrom L. Swedish obese subjects (SOS): an obesity intervention study with a nutritional perspective. Eur J Clin Nutr 1998; 52(5): 316-22.

http://dx.doi.org/10.1038/sj.ejcn.1600567

[29] McCrory MA, Fuss PJ, McCallum JE, et al. Dietary variety within food groups: association with energy intake and body fatness in men and women. Am J Clin Nutr 1999; 69(3): 4407.

[30] Underwood PJ, Belton E, Hulme P. Aversion to sucrose in obesity. Proc Nutr Soc 1973; 32(3): 93A-4A.

[31] Rodin J, Moskowitz HR, Bray GA. Relationship between obesity, weight loss, and taste responsiveness. Physiol Behav 1976; 17(4): 591-7. http://dx.doi.org/10.1016/0031-9384(76)90157-8

[32] Grinker J, Hirsch J, Smith DV. Taste sensitivity and susceptibility to external influence in obese and normal weight subjects. J Pers Soc Psychol 1972; 22(3): 320-5. http://dx.doi.org/10.1037/h0032924 
[33] Nisbett RE. Taste, deprivation, and weight determinants of eating behavior. J Pers Soc Psychol 1968; 10(2): 107-16. http://dx.doi.org/10.1037/h0026283

[34] Rodin J. Effects of obesity and set point on taste responsiveness and ingestion in humans. J Comp Physiol Psychol 1975; 89(9): 1003-9. http://dx.doi.org/10.1037/h0077193

[35] Nisbett RE. Hunger, obesity, and the ventromedial hypothalamus. Psychol Rev 1972; 79(6): 433-53. http://dx.doi.org/10.1037/h0033519

[36] Frijters JE, Rasmussen-Conrad EL. Sensory discrimination, intensity perception, and affective judgment of sucrosesweetness in the overweight. J Gen Psychol 1982; 107(2d Half): 233-47.

[37] Conner MT, Booth DA. Preferred sweetness of a lime drink and preference for sweet over non-sweet foods, related to sex and reported age and body weight. Appetite 1988; 10(1): 25-35. http://dx.doi.org/10.1016/S0195-6663(88)80030-8

[38] Bartoshuk LM, Duffy VB, Hayes JE, Moskowitz HR, Snyder DJ. Psychophysics of sweet and fat perception in obesity: problems, solutions and new perspectives. Philos Trans $\mathrm{R}$ Soc Lond B Biol Sci 2006; 361(1471): 1137-48. http://dx.doi.org/10.1098/rstb.2006.1853

[39] Duffy VB, Davidson AC, Kidd JR, et al. Bitter receptor gene (TAS2R38), 6-n-propylthiouracil (PROP) bitterness and alcohol intake. Alcohol Clin Exp Res 2004; 28(11): 1629-37. http://dx.doi.org/10.1097/01.ALC.0000145789.55183.D4

[40] Malcolm R, O'Neil PM, Hirsch AA, Currey HS, Moskowitz G. Taste hedonics and thresholds in obesity. Int J Obes 1980; 4(3): 203-12.

[41] Moskowitz HR, Kluter RA, Westerling J, Jacobs HL. Sugar sweetness and pleasantness: evidence for different psychological laws. Science $1974 ; 184(136)$ : $583-5$. http://dx.doi.org/10.1126/science.184.4136.583

[42] Pangborn RM, Bos KE, Stern JS. Dietary fat intake and taste responses to fat in milk by under-, normal, and overweight women. Appetite 1985; 6(1): 25-40. http://dx.doi.org/10.1016/S0195-6663(85)80048-9

[43] Mela DJ, Sacchetti DA. Sensory preferences for fats: relationships with diet and body composition. Am J Clin Nutr 1991; 53(4): 908-15.

[44] Cabanac M, Duclaux R. Obesity: absence of satiety aversion to sucrose. Science 1970; 168(930): 496-7. http://dx.doi.org/10.1126/science.168.3930.496

[45] Pangborn RM, Simone M. Body size and sweetness preference. J Am Diet Assoc 1958; 34(9): 924-8.

[46] Grinker J. Obesity and sweet taste. Am J Clin Nutr 1978; 31(6): 1078-87.

[47] Johnson WG, Keane TM, Bonar JR, Downey C. Hedonic ratings of sucrose solutions: effects of body weight, weight loss and dietary restriction. Addict Behav 1979; 4(3): 231-6. http://dx.doi.org/10.1016/0306-4603(79)90032-7

[48] Thompson DA, Moskowitz HR, Campbell RG. Effects of body weight and food intake on pleasantness ratings for a sweet stimulus. J Appl Physiol 1976; 41(1): 77-83.

[49] Wooley OW, Wooley SC, Dunham RB. Calories and sweet taste: effects on sucrose preference in the obese and nonobese. Physiol Behav 1972; 9(5): 765-8. http://dx.doi.org/10.1016/0031-9384(72)90048-0

[50] Drewnowski A, Brunzell JD, Sande K, Iverius $\mathrm{PH}$, Greenwood MR. Sweet tooth reconsidered: taste responsiveness in human obesity. Physiol Behav 1985; 35(4): 617-22.

http://dx.doi.org/10.1016/0031-9384(85)90150-7

[51] Salbe AD, DelParigi A, Pratley RE, Drewnowski A, Tataranni PA. Taste preferences and body weight changes in an obesity-prone population. Am J Clin Nutr 2004; 79(3): 372-8.

[52] Berridge KC. Food reward: brain substrates of wanting and liking. Neurosci Biobehav Rev 1996; 20(1): 1-25. http://dx.doi.org/10.1016/0149-7634(95)00033-B

[53] Flint A, Raben A, Blundell JE, Astrup A. Reproducibility, power and validity of visual analogue scales in assessment of appetite sensations in single test meal studies. Int $\mathrm{J}$ Obes Relat Metab Disord 2000; 24(1): 38-48. http://dx.doi.org/10.1038/sj.ijo.0801083

[54] Ekman P, Rosenberg E, editors. What the Face Reveals: Basic and Applied Studies of Spontaneous Expression Using the Facial Action Coding System (FACS). 2nd ed. New York: Oxford University Press 2005.

[55] Rosenstein D, Oster H. Differential facial responses to four basic tastes in newborns. Child Dev 1988; 59(6): 1555-68. http://dx.doi.org/10.2307/1130670

[56] Soussignan R, Schaal B, Marlier L, Jiang T. Facial and autonomic responses to biological and artificial olfactory stimuli in human neonates: re-examining early hedonic discrimination of odors. Physiol Behav 1997; 62(4): 745-58. http://dx.doi.org/10.1016/S0031-9384(97)00187-X

[57] Steiner JE, Glaser D, Hawilo ME, Berridge KC. Comparative expression of hedonic impact: affective reactions to taste by human infants and other primates. Neurosci Biobehav Rev 2001; 25(1): 53-74 http://dx.doi.org/10.1016/S0149-7634(00)00051-8

[58] Berridge KC. Measuring hedonic impact in animals and infants: microstructure of affective taste reactivity patterns. Neurosci Biobehav Rev 2000; 24(2): 173-98. http://dx.doi.org/10.1016/S0149-7634(99)00072-X

[59] Ganchrow JR, Steiner JE, Daher M. Neonatal facial expressions in response to different qualities and intensities of gustatory stimuli. Infant Behav Dev 1983; 6(2-3): 189-200. http://dx.doi.org/10.1016/S0163-6383(83)80026-5

[60] Rozin P, Lowery L, Ebert R. Varieties of disgust faces and the structure of disgust. J Pers Soc Psychol 1994; 66(5): 870-81. http://dx.doi.org/10.1037/0022-3514.66.5.870

[61] Gilbert AN, Fridlund AJ, Sabini J. Hedonic and social determinants of facial displays to odors. Chem Senses 1987; 12(2): 355-63.

http://dx.doi.org/10.1093/chemse/12.2.355

[62] Russell JA, Dols JMF, editors. The psychology of facial expression. Studies in emotion and social interaction: Cambridge University Press 1997.

[63] Ekman P, Friesen WV, editors. Facial action coding system. Salt Lake City, Utah.: Research Nexus 2002.

[64] Stice E, Spoor S, Bohon C, Veldhuizen MG, Small DM. Relation of reward from food intake and anticipated food intake to obesity: a functional magnetic resonance imaging study. J Abnorm Psychol 2008; 117(4): 924-35. http://dx.doi.org/10.1037/a0013600

[65] DelParigi A, Chen K, Salbe AD, Reiman EM, Tataranni PA. Sensory experience of food and obesity: a positron emission tomography study of the brain regions affected by tasting a liquid meal after a prolonged fast. Neuroimage 2005; 24(2): 436-43. http://dx.doi.org/10.1016/j.neuroimage.2004.08.035 